Revista Eletrônica de Direito Processual - REDP.

Rio de Janeiro. Ano 13. Volume 20. Número 1. Janeiro a Abril de 2019

Periódico Quadrimestral da Pós-Graduação Stricto Sensu em Direito Processual da UERJ

Patrono: José Carlos Barbosa Moreira (in mem.). ISSN 1982-7636. pp. 241-249 www.redp.uerj.br

\title{
DA NULIDADE DA DECLARAÇÃO DE DESERÇÃO DA INSTÂNCIA SEM PRECEDÊNCIA DE ADVERTÊNCIA À PARTE ${ }^{1}$
}

\section{THE NULLITY OF PROCEDURAL ABANDONMENT WITHOUT PREVIOUS NOTIFICATION OF THE PARTY}

José Lebre de Freitas

Professor catedrático da Faculdade de Direito da Universidade Nova de Lisboa, Portugal. Membro da International Association of Procedural Law, da Deutsch-Lusitanische Juristenvereinigung, do Instituto Ibero-Americano de Derecho Procesal e da Associazione Internazionale Giuristi di Lingua Italiana. Advogado em Portugal. E-mail: jlfreitas@1sca.pt

RESUMO: O presente artigo analisa os requisitos necessários para que seja decretada a deserção de instância no Direito Processual Civil Português, especialmente a exigência de prévia intimação da parte.

PALAVRAS-CHAVE: Nulidade; deserção de instância; Direito Processual Civil Português.

ABSTRACT: The present study aims to analyse the legal requirements for the configuration of procedural abandonment (“deserção de instância”) in Portuguese Civil Procedure, especially concerning the necessity of previous notification of the party.

KEYWORDS: Nullity; procedural abandonment; Portuguese Civil Procedure.

\footnotetext{
${ }^{1}$ Artigo recebido em 29/03/2019, sob dispensa de revisão.
} 
Revista Eletrônica de Direito Processual - REDP.

Rio de Janeiro. Ano 13. Volume 20. Número 1. Janeiro a Abril de 2019

Periódico Quadrimestral da Pós-Graduação Stricto Sensu em Direito Processual da UERJ

Patrono: José Carlos Barbosa Moreira (in mem.). ISSN 1982-7636. pp. 241-249

www.redp.uerj.br

\section{No CPC de 1961}

A deserção da instância constitui uma das causas de extinção da instância (art. 277c CPC). Era também assim nos CPC de 1939 e de 1961, onde, porém, tinha como pressuposto (agora desaparecido) uma anterior interrupção da instância.

No CPC de 1939 e, no de 1961, até à revisão de 1995-1996, impendia sobre o autor o ónus de impulso processual subsequente, de acordo com o qual "o desenvolvimento do processo tem de ser continuamente estimulado pelas partes"2. Já ALBERTO DOS REIS dizia, porém, que, apesar de incumbir "ao autor e ao réu, e principalmente ao primeiro, exercer a atividade necessária para que o processo siga os seus termos", tal não quer dizer que a atitude

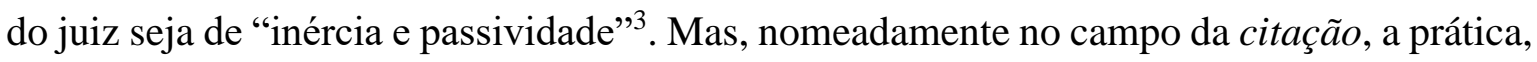
embora rigorosamente a lei não a impusesse, era no sentido de, sempre que fosse encontrado um obstáculo à sua realização, ter o autor de requerer a diligência adequada para o remover, ainda que só ao tribunal coubesse promovê-la ${ }^{4}$.

A situação alterou-se com a revisão de 1995-1996 do CPC de 1961, que passou, no então art. 265-1, a referir apenas o "ónus de impulso especialmente imposto pela lei às partes" e a fazer incidir sobre o juiz a incumbência de providenciar pelo andamento do processo, promovendo oficiosamente as diligências necessárias ao normal prosseguimento da ação e recusando o que seja impertinente ou meramente dilatório - norma que passou para o art. 6-1 do CPC atual. Assim, na falta duma lei especial que tho imponha relativamente a determinado ato, o autor não tem que impulsionar a instância; e, no caso específico da citação, houve o cuidado de expressamente determinar que incumbe à secretaria a promoção oficiosa das diligências adequadas à efetivação da citação pessoal do réu e à rápida remoção das dificuldades que obstem à realização do ato (art. 234-1 = atual art. 226-1).

Voltemos ao regime da deserção da instância anterior à revisão de 1995-1996. Davase a interrupção da instância quando o processo estivesse parado durante mais de um ano por negligência das partes em promover os seus termos, ou os de algum incidente de que

\footnotetext{
2 Manuel de Andrade, Noções de processo civil, Coimbra, Coimbra Editora, 1956, p. 360.

${ }^{3}$ Comentário ao art. 266 do CPC anotado.

${ }^{4}$ Cf. LeBre De Freitas, Parecer da Comissão de Legislação da Ordem dos Advogados sobre o Projeto de Código de Processo Civil, Revista da Ordem dos Advogados, 1990, III, p. 763.
} 
Revista Eletrônica de Direito Processual - REDP.

Rio de Janeiro. Ano 13. Volume 20. Número 1. Janeiro a Abril de 2019

Periódico Quadrimestral da Pós-Graduação Stricto Sensu em Direito Processual da UERJ

Patrono: José Carlos Barbosa Moreira (in mem.). ISSN 1982-7636. pp. 241-249

www.redp.uerj.br

dependesse o seu andamento (art. 290 do CPC de 1939; art. 285 do CPC de 1961), e tinha lugar a deserção da instância ao fim de 5 anos de interrupção (art. 296 do CPC de 1939; art. 291 do CPC de 1961); era facultado ao autor fazer cessar a interrupção, requerendo algum ato do processo ou do incidente de que dependesse o andamento dele (art. 291 do CPC de 1939; art. 286 do CPC de 1961) $)^{5}$ No CPC de 1939, ao fim de 5 anos de interrupção da instância, a deserção era declarada pelo juiz, sem o que não se produzia ${ }^{6}$; no CPC de 1961, terminados os 5 anos, a deserção dava-se automaticamente, não sendo preciso despacho judicial, mas o prazo de 5 anos contava a partir da notificação do despacho que declarava a instância interrompida, pelo que este despacho era necessário para a produção dos efeitos processuais (já não dos efeitos substantivos ${ }^{7}$ ) da interrupção ${ }^{8}$.

A revisão de 1995-1996 do CPC de 1961 manteve incólume a norma sobre a interrupção da instância. Mas, atendendo a que o autor deixou de ter, em geral, o ónus do impulso subsequente, pôs-se o problema de saber se, quando, não obstante a parte não ter o ónus, o juiz determinasse que o processo ficaria aguardando determinado ato da parte, o prazo de um ano contaria a partir da notificação desse despacho e a interrupção se produziria automaticamente com o seu decurso. Quanto à citada norma sobre a deserção, a revisão de 1995-1996 limitou-se a encurtar de 5 para 2 anos o período de interrupção a ela conducente.

Entretanto, foi-se consolidando a jurisprudência no sentido de que a interrupção da instância dependia de despacho judicial, pois as razões da paralisação deviam ser apreciadas pelo julgador ${ }^{9}$, embora se entendesse bastar um despacho que mandasse aguardar o decurso do prazo da interrupção, por conter uma decisão implícita ${ }^{10}$. Era, porém, controvertido se o despacho tinha natureza constitutiva, só com a sua notificação se iniciando o cômputo do

\footnotetext{
${ }^{5}$ Com uma diferença importante no regime de um e outro código: no de 1939 os próprios efeitos civis da prescrição e da caducidade deixavam de se verificar quando cessasse a interrupção pela declaração do autor de querer a continuação do processo, a menos que o réu se antecipasse a invocar a prescrição ou a caducidade; no de 1961 os efeitos de direito civil da caducidade mantinham-se, enquanto os da prescrição, depois de 1967, ficaram sujeitos ao regime definido no Código Civil.

${ }^{6}$ JosÉ AlBERTO dOS REIS, CPC anotado, comentário ao art. 296. Em consequência, enquanto a instância não fosse declarada extinta, as partes podiam dar impulso ao processo (JOSÉ AlBERTO DOS REIS, Comentário ao Código de Processo Civil, III, p. 440).

${ }^{7}$ José AlBerto dos ReIs, Comentário cit., III, p. 342.

${ }^{8}$ Ver, por exemplo, os acs. do TRE de 12.3.98 (JOSÉ GERALDES DE CARVALHO) e de 17.11.98 (FERNANDO BENTO), respetivamente em BMJ, 475, p. 799, e CJ, 1998, V, p. 263.

${ }^{9}$ Acs. do STJ de 13.5.03 (MoreIRA AlveS), www.dgsi.pt, proc. 03A584, de 15.6.04 (Silva SALAZAR), www.dgsi.pt, proc. 04A1992, de 8.6.06 (SEBASTIÃO PÓVOAS), www.dgsi.pt, proc. 06A1519, e de 28.2.08 (SALVADOR DA COSTA), www.dgsi.pt, proc. 08B520.

${ }^{10}$ Ac. do STJ de 14.9.06, DUARTE SOARES, www.dgsi.pt, proc. 06B2400.
} 
Revista Eletrônica de Direito Processual - REDP.

Rio de Janeiro. Ano 13. Volume 20. Número 1. Janeiro a Abril de 2019

Periódico Quadrimestral da Pós-Graduação Stricto Sensu em Direito Processual da UERJ

Patrono: José Carlos Barbosa Moreira (in mem.). ISSN 1982-7636. pp. 241-249

www.redp.uerj.br

prazo conducente à interrupção, ou natureza declarativa, limitando-se a alertar a parte para

a pendência do prazo já iniciado ${ }^{11}$.

\section{No CPC de 2013}

No novo código, seis meses de negligência do andamento do processo, quando ele dependa do impulso processual das partes, bastam para que a deserção diretamente ocorra. Este drástico encurtamento do período a decorrer até à extinção da instância (de 3 anos para 6 meses) acentua a finalidade de promoção da celeridade processual, que passa por evitar que os processos se conservem pendentes sem qualquer movimentação, nomeadamente mantendo a eles ligada a parte não onerada com o impulso processual ${ }^{12}$. Mas, por outro lado,

${ }^{11}$ No primeiro sentido: acs. do STJ de 12.1.99 (RIBEIRo COELHO), BMJ, 483, p. 167, de 30.10 .02 (DuARTE SOARES), www.dgsi.pt, 02P2756, de 15.6.04 (SILVA SALAZAR), www.dgsi.pt, proc. 04A1992, e de 8.6.06 (SEBASTIão PóvOAS), www.dgsi.pt, proc. 06A1519. No segundo sentido: acs do STJ de 2.12.93 (Miguel MONTENEGRO), www.dgsi.pt, proc. 084236), de 13.5.03 (MOREIRA ALVES), www.dgsi.pt, proc. 03A584, de 31.1.07 (GIL ROQUE), www.dgsi.pt, proc. 06B3632, de 28.2.08 (SALVADOR DA COSTA), www.dgsi.pt, proc. 08B520, e de 12.2.09 (SILVA SALAZAR), www.dgsi.pt, proc. 09A0150). Quanto à deserção, era pacífico que operava ope legis. A diferença entre os regimes da interrupção e da deserção retirava-se, literalmente, da diferente redação dos arts. 285 ("A instância interrompe-se, quando o processo estiver parado durante mais de um ano por negligência das partes em promover os seus termos ou os de algum incidente do qual dependa o seu andamento") e 291-1 ("Considera-se deserta a instância, independentemente de qualquer decisão judicial, quando esteja interrompida durante dois anos"). Ver os bem documentados acs. do TRC de 14.12.10 (GREGÓRIO SIlva JeSUS), www.dgsi.pt, proc. 48/2000.C2, e do TRG de 13.10.11 (ANTERO VEIGA), www.dgsi.pt, proc. 1789/03.0TBESP.G1. Embora as razões adiante deduzidas, por decorrência dos princípios gerais a respeitar, apontassem já para a maior adequação da primeira interpretação, a segunda era defensável com o argumento de que, abstraindo dos efeitos civis da caducidade, uma decisão de natureza declarativa sempre poria o autor de sobreaviso para as consequências do decurso dos subsequentes dois anos de interrupção, realizando a função admonitória a que a seguir me refiro. Aliás, continuava a entender-se que o prazo para a deserção se contava a partir do despacho que declarasse a interrupção (ac. do TRG de 13.10.11, www.dgsi.pt, proc. 1789/03).

${ }^{12}$ Paralelamente, as normas dos arts. $156 \mathrm{CPC}, \mathrm{n}^{\circ} \mathrm{s} 4$ e 5 (atuações compulsórias que têm como escopo o cumprimento dos prazos dos magistrados), e $162 \mathrm{CPC}, \mathrm{n}^{\circ} \mathrm{s} 4$ e 5 (idem, relativamente aos prazos da secretaria), têm finalidade semelhante. Trata-se de realizar uma função compulsória, de natureza semelhante àquela que, no direito civil, realiza a sanção pecuniária do art. 829-A CC: à ordem jurídica interessa que seja praticado determinado ato processual, assegurando o prosseguimento do processo. Por isso não faz sentido declarar deserta a instância depois de praticado, pela parte, sponte sua e ainda que após o decurso do prazo de seis meses do art. 281-1 CPC, o ato cuja omissão tenha estado na origem da paragem do processo. Já assim, embora perante prazos bem mais longos, em JOSÉ AlBERTO DOS REIS (cf. nota 5 supra). E assim tem sido entendido nos tribunais, como se vê, por último, nos acs. do TRG de 30.4.15 (JosÉ EsTelitA DE MENDONÇA), www.dgsi.pt, proc. 230/11, e do TRC de 16.3.16 (ARLINDO OLIVEIRA), www.dgsi.pt, proc. 131/04, e de 17.5.16 (FONTE RAMOS), www.dgsi.pt, proc. 2/14. Conseguida a finalidade compulsória, a subordinação do processo civil à função de realização dos direitos materiais (sempre frustrada quando, em vez dela, o processo desemboca numa decisão meramente processual) impõe que o ato seja aproveitado e o processo prossiga. Algo de semelhante se dirá se, depois de decorrido o prazo de seis meses do art. 281-1 CPC, são praticados no processo atos do tribunal (do juiz ou da secretaria) que importem o prosseguimento do processo (PAULO RAMOS DE 
Revista Eletrônica de Direito Processual - REDP.

Rio de Janeiro. Ano 13. Volume 20. Número 1. Janeiro a Abril de 2019

Periódico Quadrimestral da Pós-Graduação Stricto Sensu em Direito Processual da UERJ

Patrono: José Carlos Barbosa Moreira (in mem.). ISSN 1982-7636. pp. 241-249

www.redp.uerj.br

este encurtamento obriga a particulares cautelas na interpretação do art. 281-1 CPC e força

(para além da razão decorrente da necessidade de apreciação do requisito da negligência da parte) a que não seja dispensável um despacho judicial a alertar previamente a parte para o risco de ocorrência da deserção da instância.

Para a sua necessidade apontam logo, aliás, três elementos literais: contrariamente à norma do art. 291-1 do CPC de 1961, mas em termos semelhantes aos da do art. 285 do mesmo código, a norma do $\mathrm{n}^{\mathrm{o}} 1$ do art. 281 não contém o segmento "independentemente de qualquer decisão judicial"; esta expressão aparece, ao invés, no $\mathrm{n}^{\mathrm{0}} 5$ do mesmo artigo, segundo o qual a deserção opera na ação executiva independentemente de decisão judicial, sendo que esta situação aparece ressalvada, como excecional, no $\mathrm{n}^{\circ} 1$ ("sem prejuízo do $\mathrm{n}^{\mathrm{o}}$ 5"); o n 4 do art. 281 determina que a deserção seja julgada no tribunal onde se verifique a falta. Estes elementos tornam indiscutível a necessidade de despacho judicial, subsistindo a questão de saber se de natureza constitutiva ou meramente declarativa, nas aceções da jurisprudência anteriormente formada.

Desaparecida a figura da interrupção da instância, a primeira solução, consistente em contar o prazo de 6 meses desde a notificação dum despacho judicial que alerte para as consequências do seu decurso sem a prática do ato com que a parte é onerada, equivale, sob o prisma da extinção da instância, à configuração como declarativo do despacho de interrupção da instância no direito anterior: a parte fica alertada para a cominação que se lhe aplicará se não impulsionar o processo dentro desse prazo. Goza, além disso, das vantagens que apresentava a configuração como constitutivo do anterior despacho de interrupção da instância quando considerados os efeitos de direito civil que eram próprios da interrupção (e que agora passaram a ser consequência da deserção, por devida adaptação do disposto no art. 332-2 $\left.\mathrm{CC}^{13}\right)$.

FARIA, O julgamento da deserção da instância declarativa / Breve roteiro jurisprudencial, Julgar, Abril 2015, $\mathrm{n}^{\mathrm{o}} 4.4$, ps. 15 e 16$)$.

${ }^{13} \mathrm{O}$ prazo de caducidade do direito tem-se por suspenso com a propositura da ação, retomando a partir da deserção da instância. Na $1^{\text {a }}$ (1998) e na $2^{\mathrm{a}}$ edição (2008) do meu (com outros) CPC anotado, Coimbra, Coimbra Editora, I, no 2 da anotação ao art. 291 (do CPC de 1961), entendi que a deserção operava sem necessidade de despacho judicial. Mas, perante a supressão da figura da interrupção no CPC de 2013, passei a entender que um despacho prévio com efeito constitutivo da deserção é indispensável, dado o drástico encurtamento do prazo conducente à deserção (CPC anotado, Coimbra, Coimbra Editora, 2013, no 2 da anotação ao art. 281). 
Revista Eletrônica de Direito Processual - REDP.

Rio de Janeiro. Ano 13. Volume 20. Número 1. Janeiro a Abril de 2019

Periódico Quadrimestral da Pós-Graduação Stricto Sensu em Direito Processual da UERJ

Patrono: José Carlos Barbosa Moreira (in mem.). ISSN 1982-7636. pp. 241-249

www.redp.uerj.br

Mas a segunda solução previne também a possibilidade destes efeitos desvantajosos se se entender que, embora o prazo de 6 meses se inicie automaticamente, os efeitos do seu decurso integral não se produzem sem uma prévia advertência judicial, que deve ter lugar antes de terminado o prazo, sob pena de nulidade ${ }^{14}$, ou implicará que o ato possa ser ainda praticado dentro dum prazo adicional que o tribunal razoavelmente fixe $\mathrm{e}^{15}$.

\section{Os princípios gerais na interpretação do art. 281-1 CPC}

Constitui imperativo constitucional que os tribunais assegurem a tutela dos direitos e interesses legalmente protegidos, o que implica o primado da decisão de mérito na decisão dos conflitos de interesses privados (art. 203-2 da Constituição da República).

Daí decorre que a composição dos litígios por modo diverso da aplicação da lei material ao caso concreto (art. 203 da Constituição da República) só constitui finalidade autónoma do processo civil no julgamento de equidade ${ }^{16}$ e que, mesmo quando falte um pressuposto processual, o tribunal deve promover a sua sanação (art. 6-2 CPC), bem como dele prescindir quando, no momento da sua apreciação, nenhum outro motivo obste ao conhecimento de mérito e a decisão deva ser inteiramente favorável à parte cujo interesse a exceção dilatória se destine a tutelar (art. 278-3 CPC).

Pela mesma razão, o direito de defesa postula o tempero da rigidez das preclusões e cominações decorrentes da revelia ${ }^{17}$ e os princípios da preclusão e da autorresponsabilidade das partes são temperados por deveres de cooperação entre elas e o tribunal, para que o processo realize a sua função (de tutela dos direitos subjetivos e dos interesses legalmente protegidos) com brevidade e eficácia (art. 7-1 CPC). Este princípio da cooperação,

\footnotetext{
${ }^{14}$ Ac. do TRL de 20.12.16 (Luís FILIPE PIRES DE SOUSA), www.dgsi.pt, proc. 3422/15, que só não pôde considerar verificada a nulidade decorrente da omissão desse despacho por o autor não a ter arguido nos termos dos arts. 195 e ss, limitando-se a invocá-la (diretamente) em recurso. Também o ac. do TRL de 9.7.15 (MARIA TERESA AlBuQUERQUE), www.dgsi.pt, proc. 886/06, entende que a deserção da instância não pode ser declarada sem essa prévia advertência, tendo julgado procedente a nulidade invocada em virtude da sua falta. ${ }^{15}$ Ac. do TRL de 26.2.15 (ONDINA CARMO ALVES), www.dgsi.pt, proc. 2254/10, que fixou 15 dias para o efeito. Em PAUlo RAMOS DE FARIA, cit., no 5.2 (p. 18), lê-se que o prazo será de 10 dias, se outro o juiz não fixar, o que também entendeu o ac. do TRP de 2.2.15 (MANUEL DomingOS FERNANDES), proc. 4178/12.

${ }^{16}$ LeBre De FreITAS, Introdução ao Processo Civil, Coimbra, Coimbra Editora, 2013, n's I.3.4.

${ }^{17} \mathrm{Idem}, \mathrm{n}^{\mathrm{O}} \mathrm{S}$ I.2.31 e I.2.3.4.
} 
Revista Eletrônica de Direito Processual - REDP.

Rio de Janeiro. Ano 13. Volume 20. Número 1. Janeiro a Abril de 2019

Periódico Quadrimestral da Pós-Graduação Stricto Sensu em Direito Processual da UERJ

Patrono: José Carlos Barbosa Moreira (in mem.). ISSN 1982-7636. pp. 241-249

www.redp.uerj.br

finalmente introduzido no CPC de 1961 em 1995-1996, aparece acentuado no CPC de 2013 no que respeita aos deveres do juiz ${ }^{18}$, entre os quais o dever de prevenção ${ }^{19}$.

A advertência às partes das possíveis consequências desvantajosas de certas atuações (cf. arts. 590-4 CPC e 591-c CPC) e a própria garantia, pelo juiz, dum contraditório efetivo (art. 3-3 CPC) são manifestações também deste dever de cooperação. O mesmo se pode dizer da imposição de transparência nos atos de comunicação entre o tribunal e as partes (cf., por exemplo, os arts. 131-4 e 219-3 do CPC), as garantias destas perante as omissões e erros do tribunal (cf. arts. 157-6 e 191, nº 2 e 3, do CPC) e a imposição das formalidades a observar no ato de citação (art. 227 CPC).

Fora do Direito Processual Civil, a imposição ao credor da fixação ao devedor dum prazo admonitório antes de poder invocar o incumprimento definitivo do contrato, apesar da mora já ocorrida (art. 808-1 CC), a concessão ao promitente perante o qual foi feita a resolução do contrato da faculdade de excecionar ainda a vontade de o cumprir (art. 830-5 CC) ou o dever de supressão oficiosa, pelos órgãos e agentes administrativos, das deficiências dos requerimentos dos interessados, a fim de evitar que estes sofram prejuízos decorrentes de irregularidades ou imperfeições (art. 76-2 CPA), são manifestações paralelas dum princípio geral do sistema jurídico que limita as consequências desvantajosas dos atos e omissões dos sujeitos de direito com o fim de lhes possibilitar ainda a efetivação dos seus direitos. Ora, ao longo dos anos, este princípio geral tem sido progressivamente acentuado na lei processual e na sua interpretação. Com ele de modo algum se conciliam interpretações da lei que, longe de se inserirem no percurso histórico atrás sumariado, recuam a soluções há muito afastadas ${ }^{20}$.

O despacho judicial que advirta a parte para a possibilidade da deserção da instância não é, pois, dispensável, quer se entenda que só a partir dele correm os seis meses do art.

\footnotetext{
${ }^{18}$ Assim, por exemplo, no art. 590-4 CPC quanto ao poder, agora vinculado, de convidar a aperfeiçoar os articulados, ou no art. 6-1 CPC quanto à direção formal do processo ("cumpre ao juiz ..."). A cooperação era já afirmada como dever geral do juiz, desde a revisão de 1995-1996, no art. 265 do CPC de 1961, de cujo nº 1 foi transposta a regra do art. 7-1 do atual código.

19 Sobre ele: TeIXEIRA DE SouSA, Estudos sobre o novo processo civil, Lisboa, Lex, 1997, p. 66. Em Jurisprudência (75) - Teixeira de Sousa, https://blogippc.blogspot.pt/, este autor aplica o dever de prevenção ao caso da deserção da instância, entendendo que o juiz deve prevenir a parte quando, por exemplo, ela "tiver demonstrado, pelo seu anterior comportamento processual, que está interessada na continuação do processo e se, por isso, for surpreendente a falta de impulso processual".

${ }^{20}$ Veja-se, designadamente, as notas 4 e 5 supra, bem como os cuidados havidos, na vigência do CPC de 1961, com a interpretação do regime da interrupção da instância.
} 
Revista Eletrônica de Direito Processual - REDP.

Rio de Janeiro. Ano 13. Volume 20. Número 1. Janeiro a Abril de 2019

Periódico Quadrimestral da Pós-Graduação Stricto Sensu em Direito Processual da UERJ

Patrono: José Carlos Barbosa Moreira (in mem.). ISSN 1982-7636. pp. 241-249

www.redp.uerj.br

281-1 CPC, quer se entenda que basta que o juiz o profira, no decurso desse prazo ou depois dele concluído, desde que a parte tenha a possibilidade de praticar seguidamente o ato omitido $^{21}$. A jurisprudência, acima referida, que se tem formado em torno da interpretação do art. 281-1 CPC, na linha da anterior interpretação dominante do art. 285 do CPC de 1961, é, pois, aquela que se conforma com a Constituição da República e com os princípios gerais do atual sistema do processo civil português.

A norma do art. 281-1 CPC tem assim sete requisitos, dos quais seis evidenciados na letra do seu texto e o último decorrente da sua interpretação à luz dos referidos princípios gerais:

1. Que lei especial, ou o tribunal por despacho de adequação formal do processo, imponha à parte um ónus de impulso processual subsequente;

2. Que o ato que a parte deva praticar seja por ela omitido;

3. Que o processo fique parado em consequência dessa omissão;

4. Que a omissão se prolongue durante mais de seis meses;

5. Que o processo se mantenha, por isso, parado durante este período de tempo;

6. Que a omissão seja imputável à parte, por dolo ou negligência;

7. Que o juiz alerte a parte onerada para a deserção da instância que ocorrerá se o ato não for praticado (segundo a corrente mais exigente, só a partir da notificação deste despacho de advertência se contando os seis meses).

\section{A consequência da nulidade}

Ocorrendo os sete requisitos da norma do art. 281-1 CPC que acabam de ser apontados, o juiz julga deserta a instância.

Ocorrendo os seis primeiros requisitos, mas não sendo feita a advertência judicial à parte, se o juiz proferir o despacho a declarar deserta a instância, verifica-se a omissão de um ato que devia ser praticado antes dessa declaração, pelo que este é nulo nos termos do

\footnotetext{
${ }^{21}$ Para PAUlo RAMOS DE FARIA, cit., no 5 (ps. 16 a 18), violado este dever de prevenção do juiz, a decisão que declare deserta a instância constitui uma decisão-surpresa, não afastada com o contraditório subsequente à deserção, chegando ele assim, com outro fundamento, a um resultado idêntico (a subsequente nulidade).
} 
Revista Eletrônica de Direito Processual - REDP.

Rio de Janeiro. Ano 13. Volume 20. Número 1. Janeiro a Abril de 2019

Periódico Quadrimestral da Pós-Graduação Stricto Sensu em Direito Processual da UERJ

Patrono: José Carlos Barbosa Moreira (in mem.). ISSN 1982-7636. pp. 241-249

www.redp.uerj.br

art. 195-1 CPC: o ato processual da notificação à parte constitui pressuposto do despacho de deserção.

Não é que os outros requisitos não sejam também pressupostos do ato jurisdicional de declaração da deserção da instância; mas só esse constitui a prática dum ato processual e é por isso o único cuja falta integra o conceito de nulidade processual do art. 195-1 CPC, que tem como referência a sequência processual e como elemento definidor (fora a omissão de formalidades), não só a prática dum ato totalmente proibido ou a omissão dum ato necessário do processo, mas também o desrespeito pelo momento processual em que o ato pode ou deve ser praticado $^{22}$ : a lei, na interpretação acabada de fazer, só admite que o despacho de deserção seja proferido depois da advertência à parte. A prolação do despacho de deserção sem que se verifiquem os seis restantes pressupostos fere-o, sem dúvida, de nulidade à luz do conceito geral do direito civil (art. 294 CC), mas processualmente tal constitui um erro de julgamento, só sindicável em recurso.

\section{REFERÊNCIAS BIBLIOGRÁFICAS:}

ANDRADE, Manuel de. Noções de processo civil, Coimbra, Coimbra Editora, 1956.

FREITAS, Lebre de. Parecer da Comissão de Legislação da Ordem dos Advogados sobre o Projeto de Código de Processo Civil, Revista da Ordem dos Advogados, 1990, III. FREITAS, José Lebre de. Introdução ao Processo Civil, Coimbra, Coimbra Editora, 2013.

FREITAS, José Lebre de. ALEXANDRE, Isabel. CPC anotado, Coimbra, Coimbra Editora, 2014.

REIS, José Alberto dos. Comentário ao Código de Processo Civil, III.

SOUSA, Teixeira de. Estudos sobre o novo processo civil, Lisboa, Lex, 1997.

\footnotetext{
${ }^{22}$ LEBRE DE FREITAS - ISABEL ALEXANDRE, CPC anotado, Coimbra, Coimbra Editora, 2014, I, nº 2 da anotação ao art. 195. Para determinar a ocorrência da nulidade consistente na prática dum ato processual, há que verificar se a forma do processo em que o ato foi praticado o consentia naquele momento sequencial (LEBRE DE FREITAS, Introdução ao processo civil, Coimbra, Coimbra Editora, 2013, $\mathrm{n}^{\circ}$ I.2.3, p. 23).
} 